\title{
Tekrarlayan Aspirasyon Pnomonisinin Nadir Bir Nedeni: Pulmoner Arter Sling
}

\author{
Pulmonary Artery Sling: A Rare Cause of Recurrent Aspiration Pneumonia
}

Abdullah Özyurt, Ali Baykan, Ertuğrul Mavili* Faruk Serhatlıoğlu**, Mustafa Argun, Kazım Uzum, Nazmi Narin

Erciyes Üniversitesi Tıp Fakültesi, Pediatrik Kardiyoloji Bilim Dall, Kayseri, Türkiye

*Erciyes Üniversitesi Tıp Fakültesi, Radyoloji Anabilim Dalı, Kayseri, Türkiye

**Erciyes Üniversitesi Tıp Fakültesi, Kalp Damar Cerrahisi Anabilim Dalı, Kayseri, Türkiye

\footnotetext{
Yazışma Adresi/Address for Correspondence Dr. Abdullah Özyurt, Erciyes Üniversitesi Tip Fakültesi, Pediatrik Kardiyoloji Bilim Dall, Kayseri, Türkiye GSM.: +9050574566 21 E-posta:duruozyur!@yahoo.com.tr Geliş Tarihi/Received: 24.01.2013 Kabul Tarihi/Accepted: 4.02 .2013

"Bu yazı $46^{\text {th }}$ Annual Meeting of the Association for European Paediatric and Congenital Cardiology-23-26 May 2012, istanbul'da poster bildirisi olarak sunulmuştur

(c) Güncel Pediatri Dergisi, Galenos Yayınevi tarafindan basilmıștir.

(c) The Journal of Current Pediatrics, published by Galenos Publishing.
}

\begin{abstract}
ÖZET
Pulmoner arter sling (PAS), sol pulmoner arterin sağ pulmoner arter arka kısmından köken alarak anormal seyirle sol akciğer hilusunda sonlandığı en nadir vasküler ring anomalisidir. Altı aylık bir kız olgu beslenmeyi takiben öksürük, nefes darlığı, hırıltı ve morarma şikâyetleriyle acil ünitemize getirildi. Aspirasyon pnömonisi tanısı ile yatıılan olgunun sol ana bronşundan bronkoskopiyle katı yemek artıkları çıkarıldı. Onbeș aylıkken aynı șikâyetlerle ikinci başvurusunda çekilen toraks tomografisiyle PAS tanısı konuldu. Toraks tomografisinde ayrıca sol ana bronş basısı ve hipoplazisi vardı. On beş aylıkken cerrahi yolla slingi düzeltildi. Cerrahi sonrası solunum ve beslenme şikâyetleri olmadı. En son kontrolünde 22 ayllk olan hasta polikliniğimizde sorunsuz olarak izlenmektedir. Pulmoner arter sling, daha çok tekrarlayan wheezing atakları, inaţ̧ı öksürük, kronik stridor, kusma ve disfaji gibi şikâyet ve bulgularla başvurur. Tekrarlayan aspirasyon pnomonisi kliniğinde PAS tanısı nadirdir. Anormal seyirli sol pulmoner arter, seyri nedeniyle trakea veya sağ pulmoner artere bası yapar. Olgu atipik anatomisi ve prezantasyonu nedeniyle sunulmuştur. (Güncel Pediatri 2013; 11: 81-4)
\end{abstract}

Anahtar kelimeler: Sling, tekrarlayan aspirasyon pnomonisi, stridor, pulmoner arter

\section{SUMMARY}

Pulmonary artery sling is the rarest vascular ring anomaly that left pulmonary artery originates from posterior of right pulmonary artery with an abnormal course and ends in hilus of the left lung. A Six months old girl was brought to our emergency unit for cough, dyspnea, and cyanosis which were started after feeding. She was hospitalized with the diagnosis of aspiration pneumonia and solid food remnants were aspirated from the left main bronchus by bronchoscopy. In her second hospitalization when she was 15 months old, pulmonary artery sling was seen in her thoracic tomography and was corrected by surgery. Hypoplasia and compression of left main bronchus were also noted in her thoracic tomography. She was 22 months old on her last visit and is followed by our outpatient clinic without any problems. Recurrent wheezing episodes, brassy cough, chronic stridor, vomiting, and dysphagia are the main presenting signs and symptoms of pulmonary artery sling. PAS diagnosis is rare for recurrent aspiration pneumonia. Due to abnormal course of the left pulmonary artery it presses over trachea or right pulmonary artery. The presentation of this case was considered for its atypical anatomy and clinical presentation. (Journal of Current Pediatrics 2013; 11: 81-4)

Key words: Sling, recurrent aspiration pneumonia, stridor, pulmonary artery

\section{Giriş}

Pulmoner arter sling (PAS), sol pulmoner arterin, sağ pulmoner arter arka kısmından köken alarak, sağ ana bronş üzerinde seyrettikten sonra, trakea veya karinanın arkasında ve özefagusun önünde ilerleyip sol akciğer hilusunda sonlandığı konjenital bir anomalidir (1). Literatürde az sayıda vaka serisi olsa da PAS olguları genellikle olgu sunumları şeklindedir. Bir saha taramasında sıklığı 56:1.000.000 olarak bildirilmiştir (2). Olguların hemen tamamında sağ ana bronş ve/veya trakea basısı görülür. Sol ana bronş basısı ise nadirdir (1-3). Bildiğimiz kadarıyla literatürde tekrarlayan aspirasyon pnömonileri ile sunulan PAS olgusu yer almamaktadır.

Bu sunumda, tekrarlayan aspirasyon pnömonisi olan, toraks tomografisinde sol ana bronş basısı saptanan ve cerrahi olarak PAS'i düzeltilen 15 aylık bir kız olgu sunularak tekrarlayan aspirasyon pnömonilerinde PAS anomalisine dikkat çekilmiştir. 


\section{Olgu}

Illk kez 6 aylıkken beslenme sırasında öksürük, morarma ve nefes darlığı şikâyetleri olan hasta bir sağılı merkezinden aspirasyon pnömonisi ön tanısıyla acil servisimize gönderildi. Akciğer filminde parakardiyak nonspesifik infiltrasyonlar mevcuttu. Şikâyetlerinin beslenmeyle ilişkili olması nedeniyle bronkoskopi yapııdı. Sağ bronştan katı yemek artıkları çıkarıldı. Sol ana bronşa, kalibrasyonunun ince olması nedeniyle girilemedi. Hastaya sol ana bronş darlığının etiyolojisini belirlemek amacıyla -olası vasküler ring açısından- toraks tomografisi planlandı. Aile onamı alınamadığı için çekilemedi. Hasta antibiyotik, nemli oksijen ve destek tedavileri ile 9 gün sonra semptom ve bulguları düzelmiş olarak taburcu edildi.

Olgunun 4 ay anne sütüyle, 4 aylıktan sonra anne sütü ve ek gıdalarla beslendiği, beş ve 8 aylıkken pnömoni tanısı ile 2 kez başka bir merkezde yatarak tedavi gördüğü, her ikisinde de kașıkla beslenirken beslenmenin sonuna doğru öksürük, kusma ve morarmayı takiben hastaneye götürüldüğü öğrenildi.

Olgu onbeş aylıkken hastanemize ikinci kez, beslenmeyi takiben, son 24 saattir öksürük, ateş, nefes darlığı ve morarma şikâyetleriyle başvurdu. Fizik incelemesinde şuuru açık ancak huzursuzdu. Ağırlığı 7500 gr (<3. P), boyu $72 \mathrm{~cm}$ (10. P), kalp tepe atımı 158/dk ve ritmik, solunum sayısı $72 / \mathrm{dk}$ ve ateşi $38^{\circ} \mathrm{C}$ ölçüldü. Interkostal çekilmeleri, stridoru, hafif dehidratasyonu vardı. Kapiller oksijen satürasyonu $\% 90$, venöz kan gazında PCO2 68 mmHg olarak bulundu. Yoğun bakım ünitesinde ventilasyon desteği olmadan kan gazı değerleri normal düzeylerine ulaşan hastaya tekrarlayan aspirasyon pnömonisi nedeni ile yapılan hemogram, böbrek-karaciğer fonksiyon testleri, ter testi, serum immunglobulin düzeyleri normal saptandı. PPD testinde $5 \mathrm{~mm}$ endürasyon saptandı. Ekokardiyografik incelemede parasternal kısa eksende sol pulmoner arter görüntülenemedi. Toraks tomografisinde, sol pulmoner arterin sağ pulmoner arterden köken aldığı, sol pulmoner arterin retrotrakeal seyri sırasında sol ana bronşa bası yaptığı, sol ana bronşun basıya uğradığı düzeyde kalibrasyonunun azaldığı belirlendi (Resim1a).

Hastaya PAS tanısı konuldu ve bir hafta sonra göğüs ve kalp damar cerrahisi ekipleriyle birlikte ameliyata alındı. Kardiyopulmoner by-pass altında median sternotomi ile kalbe ulaşıldı. Sol pulmoner arter, çevre dokulardan ayrılarak görüldü ve sağ pulmoner arter bağlantısı kaldırılarak trakea ve özefagus arasından çıkarıldı. Ana pulmoner artere anastomoz edildi. Eş zamanlı olası trakeobronşiyal darlığa cerrahi müdahale açısından bronkoskopi yapıldı. Hava yollarında darlık saptanmadı. Olgu cerrahi sonrası aynı gün ekstübe edildi, dördüncü gün ise taburcu edildi. Bir ay sonraki ekokardiyografi ve toraks tomografisi incelemeleri (Resim 1b) normal olarak değerlendirildi. En son kontrolünde 22 aylık olan hastanın cerrahi sonrası stridoru bir süre devam etti; beslenme intoleransı, öksürük, nefes darlığı, morarma şikâyeti olmadı, pnömoni atağı gözlenmedi. Stridorunun bir süre devam etmesi bası sonucu oluşan geçici sekonder trakeobronkomalaziye bağlandı.

\section{Tartışma}

Pulmoner arter sling, vasküler ring anomalilerinin en nadir formudur (4). Semptomatik hastalar hava yolları ve/veya özefagus bası semptomları ile başvurur. Sol pulmoner arter, sağ pulmoner arterin bir dalı şeklindedir ve çapı normalden daha küçüktür, sağ pulmoner arterden ayrıldıktan sonra, karinanın biraz üzerinden, trakea ve özefagusun arasından seyrederek sol akciğer hilusuna uzanır. Trakea ve sağ ana bronşun arka kısımları ile özefagusun ön kısmına bası yapar (1-5). Olgumuzun toraks tomografisinde PAS için tipik olmayan sol ana bronş basısı vardı. Sol ana bronş basısı literatürde birkaç olguda daha bildirilmiştir (3).

Pulmoner arter sling olgularının yarısından çoğunda trakeobronkomalazi, sağ akciğerde hipoplazi, sağ, çok nadiren de sol akciğer aplazisi görülür (3-6). Sol akciğer hilusunun normalden daha aşağıda yerleşmesi dikkat çekicidir. Yarısında ise patent duktus arteriozus, atriyal septal defekt, Fallot tetralojisi, sol persistan vena kava superior gibi kardiyovasküler anomaliler saptanır. Daha az bir kısmıysa olgumuzda olduğu gibi izole PAS şeklindedir (7).

Çocuklarda tekrarlayan pnömoni tanımı, yılda iki ve daha fazla veya herhangi bir zaman diliminde üç ve daha

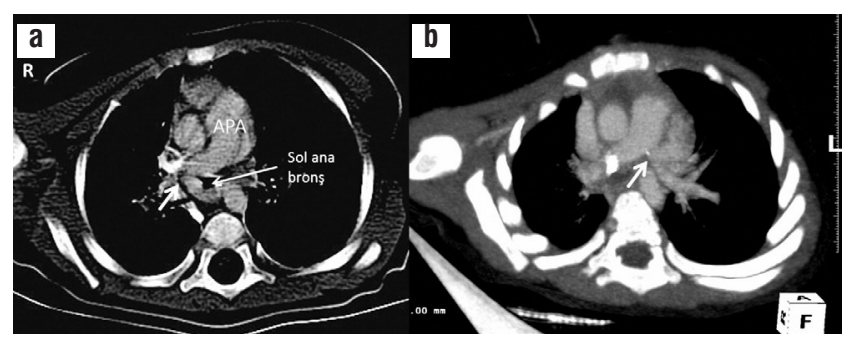

Resim 1. a) Illk resimde toraks tomografisinde sol pulmoner arter, ana pulmoner arterin devamı olarak izlenen sağ pulmoner arterden çıkarak (kalın kısa ok) sol akciğere doğru yönleniyor. Sol pulmoner arter sağ pulmoner artere göre daha hipoplazik izleniyor. Seyri sırasında sol ana bronşa bası yapıyor (ince uzun ok).

b) Sol pulmoner arterin, sol ana bronş önünden alınarak ana pulmoner artere anastomoz edildiği görülüyor 
fazla atak görülmesi olarak yapıımıştır. Çocuklarda yaşa bağlı olmakla birlikte; immün yetmezlik, astım bronşiale, aspirasyon sendromları, yutma disfonksiyonları, bronkopulmoner displazi, konjenital kalp hastalıkları, mukosilier bozukluklar, nöromuskuler hastalıklar, gastroözefageal reflü vb tekrarlayan pnömonilerin sık nedenleridir. Birçok nedenle karşımıza çıkan tekrarlayan aspirasyon sendromları, tekrarlayan pnömonilerin nadir nedenleri arasındadır (8). Hastamızda da tekrarlayan pnömonilerin sık sebepleri öykü, fizik muayene, laboratuvar testleri ve basit görüntüleme yöntemleriyle dışlandı. Vasküler ring anomalisi şüphesiyle çekilen toraks tomografisinde ise PAS tanısı doğrulandı.

Izole PAS'da klinik belirtiler olguların \%85'inde hayatın ilk bir ayı içerisinde ortaya çıkmaktadır. Bu da pulmoner arter basıncının fizyolojik sınılara düşmeye başladığ ve pulmoner arterin volüm etkisiyle genişleyerek bas semptomlarını artırdığı döneme denk gelir. Kliniğin başlangıç zamanını eşlik edebilen trakeal ve kardiyak anomaliler de etkiler. Izole PAS olguları kliniğe inatçı öksürük, wheezing atakları, kronik stridor, gürültülü solunum, kusma, disfaji, pnömoni atakları ve atelektaziler gibi bronş/trakea/özefagus basısı semptom ve bulguları ile başvurur. Olgumuzda olduğu gibi beslenmeyle ilişkili semptomlar daha nadirdir $(2,7,9,10)$.

Bulgular PAS olgularına özgü olmadığı veya bazı hastalar uzun dönem asemptomatik seyrettiği için tanı gecikebilmektedir $(9,10)$. Olgumuzda toraks tomografisi için aileden aydınlatımış onam alınamadığı için tanı ancak 15 aylıkken konulabilmiştir.

Tanıda kliniğin yanında akciğer grafisi, ekokardiyografi, baryumlu pasaj grafisi, CT, MR ve konvansiyonel anjiyografiden yararlanılır. Akciğer grafilerinde trakeada sola deviasyon, sol akciğer hilusunun normale göre daha aşağıda yerleşmesi ve iki akciğer arasında havalanma farkı izlenebilir. Obstrüksiyonun tam olduğu durumlarda atelektaziler gözlenebilir. Lateral grafide trakea ile özefagus arasında orta mediastende bir kitle görünümü olabilir. Baryumlu özefagografi lateral görüntülemesinde karinanın hemen üzerinde izlenen anterior özefagus basısı oldukça tipiktir. Ekokardiyografiyle de sol pulmoner arterin ana pulmoner arterden ayrılmadığı görülebilir. Bronkoskopinin tanı değeri düşüktür $(2-5,10,13)$. Olgumuzun akciğer grafisinde parakardiyak alanda non-spesifik infiltratif görünümler vardı. Ekokardiyografik incelemede parasternal kısa eksende sol pulmoner arter ile ana pulmoner arter ilişkisinin olmadığı görüldü. Bronkoskopide sol ana bronş kalibrasyonunun azalmış olması PAS için tipik bir bulgu olmasa da vasküler ring anomalilerini düşündürmüștü.
Özellikle tomografi ve manyetik rezonans, PAS tanısında ve eşlik eden hava yolu anomalilerinin belirlenmesinde, varsa trakeobronşial darlığın ciddiyetini ve uzunluğunu saptamada ve operasyon stratejisinin planlanmasında non-invaziv önemli tanı yöntemleridir $(5,11,13)$. Olgumuzda da PAS tanısı toraks tomografisi ile konuldu ve cerrahi düzeltmeden sonraki normal anatomisi de toraks tomografisiyle görüntülendi.

Radyolojik olarak önemli hava yolu darlığı gösterilen semptomatik PAS hastaları cerrahiyle düzeltilmelidir. Pulmoner arter sling cerrahi tedavisinde medyan veya lateral sternotomi kullanılarak anormal sol pulmoner arterin kesilmesi ve trakeanın önünde uç-uca veya ana pulmoner artere uç-yan anastomozu tekniği kullanılır. Bu esnada sol pulmoner arterde rotasyon veya kink olmamasına dikkat edilmelidir. Olguların neredeyse \%90'ında trakeoplasti gereksinimi olur (12). Olgumuzda da medyan sternotomi ile kardiyopulmoner by-pass altında sol pulmoner arter sağ pulmoner arterden ayrıldı ve trakeanın önüne alındıktan sonra ana pulmoner artere uç-yan anastomoz edildi. Trakeoplasti yapılmadı, sol ana bronştaki hafif darlığa müdahale edilmedi.

PAS erken tanı ve cerrahi tedavi ile düzeltilebilir bir anomali olmasına rağmen, tanısı geciken olgularda cerrahi mortalite \%40'lara kadar çıkmaktadır (11-13). Bu olguların tekrarlayan aspirasyonlara bağıı pnömoni atakları ile başvurması oldukça nadirdir. Anormal çıkış ve seyir gösteren sol pulmoner arterin sol akciğer hava yollarına bası yapması da çok beklenmez. Toraks tomografisiyle tanısı konulduktan sonra cerrahiyle düzeltilen 15 aylık PAS olgusu bu nadir klinik görünümü ve atipik sol ana bronș basısı nedeni ile sunulmuştur.

\section{Kaynaklar}

1. Contro S, Miller RA, White M, Potts WJ. Bronchial obstruction due to pulmonary artery anomalies. I. Vascular sling. Circulation 1958; 17:418-23.

2. Yu JM, Liao CP, Ge S, Weng ZC, Hsiung MC, Chang JK, et al. The prevalence and clinical impact of pulmonary artery sling on school-aged children: a large-scale screening study. Pediatr Pulmonol 2008;43:656-61.

3. Oguz B, Alan S, Ozcelik U, Haliloglu M. Horseshoe lung associated with left-lung hypoplasia, left pulmonary artery sling and bilateral agenesis of upper lobe bronchi. Pediatr Radiol 2009;39:1002-5.

4. Dodge-Khatami A, Tulevski II, Hitchcock JF, de Mol BA, Bennink GB. Vascular rings and pulmonary arterial sling: from respiratory collapse to surgical cure, with emphasis on judicious imaging in the hi-tech era. Cardiol Young 2002;12:96-104.

5. Chen SJ, Lee WJ, Lin MT, Wang JK, Chang $\mathrm{Cl}$, Chiu IS, et al. Left pulmonary artery sling complex: computed tomography and hypothesis of embryogenesis. Ann Thoac Surg 2007;84:1645-50. 
6. Kelly AC, Philip MB, David AW, Armin E. Tracheomalacia and traceobronchomalacia in children and adults: an in-depth review. Chest 2005;127:984-1005.

7. Collins RT 2nd, Weinberg PM, Goldmuntz E, Harris M. Images in cardiovascular medicine. Partial anomalous left pulmonary artery. Circulation 2009;119:2405-7

8. Owayed AF, Campbell DM, Wang EE. Underlying causes of recurrent pneumonia in children. Arch Pediatr Adolesc Med 2000;154:190-4.

9. Ma GQ, Li ZZ, Li XF, Peng Y, DU ZD, Jin LZ, et al. Congenital vascular rings: a rare cause of respiratory distress in infants and children. Chin Med J 2007;120:1408-12.

10. Uçar S, Zorlu P, Metin O, Orün UA. Pulmonary artery sling as a cause of recurrent wheezing in children. Tuberk toraks 2010;58:311-5
11. Song ZW, Xu CY, Ge W, Zhao YP, Chen MK, Wu AQ, et al. The diagnostic value of MSCT multi-dimensional reconstructions for congenital vascular ring with tracheal stenosis. Zhonghua Yi Xue Za Zhi 2011;91:619-22.

12. Backer CL, Russell HM, Kaushal S, Rastatter JC, Rigsby CK, Holinger LD. Pulmonary artery sling: current results with cardiopulmonary bypass. J Thorac Cardiovasc Surg 2012;143:144-51.

13. Wang JH, Ding GC, Zhang MY, Liu M, Niu HY. Clinical and imaging features of pulmonary artery sling in infants without significant hemodynamic changes. Chin Med J (Engl) 2011;124:3412-4. 